\title{
Summa/historia: disolución y reconstitución en la historiografía de la arquitectura (1970-1978)
}

\section{Summa/historia: Disolution and Reconstitution in the Argentinean Architectural Historiography (1970-1978)}

Juan Sebastián Malecki* Instituto de Humanidades. Universidad Nacional de Córdoba /Conicet j.sebamalecki@gmai.com 


\section{Resumen:}

En julio de 1974 salió el primer fascículo que oficiaba como introducción de los capítulos de Summa/ historia que saldrían hasta 1977, luego reunidos en el libro Documentos para una historia de la arquitectura Argentina. En él, Waisman explicitaba que S/h se articularía a partir de los planteos realizados en La estructura histórica del entorno que le había permitido posicionarse en la escena nacional. El contexto de producción de $S / h$ nos permite analizar un momento muy particular en el proceso de constitución del campo de la historiografía de la arquitectura. Si durante los sesenta se apreciaba una consolidación en la producción historiografía, los setenta supusieron un momento de crisis y "disolución", seguido de una relativamente rápida reconstitución, en la cual $S / h$ tuvo un papel central, no sólo porque ofrecía una mirada integradora de la historia de la arquitectura en el país, no ensayada hasta el momento, sino también porque dinamizó redes y contactos que se prolongaron en el tiempo.

Palabras clave: Waisman, Summa/historia, Historiografía

\section{Abstract:}

In July 1974, was published the first instalment that acted as an introduction for the Summa/historia's $(S / h)$ chapters that were going to be published until 1977, later reunited in the book Documentos para una historia de la arquitectura argentina. In that July instalment, Waisman explained that her book La estructura historica del entorno -which allowed to position herself in the national architectural scenewas going to be the theoretical framework for $s / h$. S/h's context of production is relevant to study a very particular moment in the constitution process of the architectural historiography field. Whereas during the 60's a consolidation in the historiographical production can be appreciated, the 70's meant a moment of crisis and "dissolution". This was followed by a relatively quick reconstitution of the architectural historiography field, in which $s / h$ had a central roll, not only because it offered the first comprehensive national architectural history, but also because it triggered and consolidated networks and contacts that were prolong in time.

Key words: Waisman, Summa/historia, Historiography. 


\section{Presentación}

En un número de 1980 de la revista Summa dedicado a analizar la década del setenta, Marina Waisman (1980: 65) sostenía que

"llegamos a otras de las grandes desdeñadas del quinquenio pasado, trasladada ahora a un sitio de honor: la historia de la arquitectura. Mirada entonces como la glorificación de las clases dominantes del pasado por el estudio de los monumentos erigidos al poder y el prestigio, es ahora recuperada como patrimonio común que ayuda a la identificación de la nacionalidad".

Con este comentario, Waisman reconocía el conflictivo derrotero seguido por la "historia", en el que, en un breve lapso, había cambiado su status, pasando de una posición marginal a ocupar un lugar central en los debates que fueron modelando una reconfiguración disciplinar que ya era evidente para principio de los ochenta. Lo que la cita no dice, es el papel que tuvo la propia Waisman $^{2}$-y una de sus principales iniciativas, Sum$\mathrm{ma} /$ historia $(S / h)$ - en la rehabilitación de la historia en los debates locales. Que tal emprendimiento se haya realizado desde Summa no es un dato menor, en tanto la revista, desde su aparición en 1963, se constituyó en una de las principales empresas de la cultura arquitectónica argentina de la segunda mitad del siglo XX, mostrando una gran porosidad para captar tendencias, dar a conocer nuevas perspectivas e intervenir en los principales temas del momento.

En julio de 1974 salió el primer fascículo que oficiaba como introducción y marco general de los capítulos que iban a ir saliendo en Summa hasta $1977^{3}$, luego reunidos en el libro Documentos para una historia de la arquitectura Argentina (Fi-

1 Quiero agradecer los comentarios de Graciela Silvestri, Ana Sanchez Trolliet y muy especialmente a Alberto Nicolini que me aportó generosamente sus recuerdos y vivencias.

2 Marina Kitroser de Waisman (1920-1997) egresó como arquitecta en 1945, ingresando como adjunta de Historia de la Arquitectura en la entonces Escuela de Arquitectura de la Universidad Nacional de Córdoba en 1947, a pesar de no tener ninguna simpatía por el peronismo, en un momento en el que el rechazo o la adscripción política determinaban el egreso o el ingreso a la Universidad. Conocida por su apellido de casada, tuvo mucha más repercusión que su esposo, Abraham Waisman -filósofo y docente de la Facultad de Filosofía y Humanidades-. Luego de su alejamiento de la Universidad Nacional de Córdoba en 1973, recayó en la Universidad Católica de Córdoba. En 1972 se convirtió en colaboradora permanente de Summa, desde donde realizó diversos emprendimientos. Además de s/h, Waisman llevó adelante, a partir de 1977, los Summarios, una de las mayores empresas de traducción y difusión en la cultura arquitectónica argentina.

3 Summa, $n^{\circ} 78,1974$ gura 1), la primera historia general de la arquitectura del país. Allí Waisman explicitaba que $S / h$ se articularía a partir de los planteos realizados en La estructura histórica del entorno de 1972 que le había permitido posicionarse en la escena nacional. Lo interesante del libro es que no sólo procuraba ser una respuesta a lo que ella entendía era la crisis que vivía la arquitectura, sino que también era pensado como una reacción al contexto de radicalización del Taller Total de la Facultad de Arquitectura de Córdoba. Más aún, leído en este contexto, La estructura histórica daba cuenta de un conjunto de apuestas teóricas que buscaban conformar un nuevo objeto historiográfico que se asentaba, además, sobre una serie de rupturas previas.

Por tanto, el contexto de producción de s/h nos permite analizar un momento muy particular en el proceso de constitución del campo de la historiografía de la arquitectura. Si durante los sesenta se puede apreciar una consolidación en la producción historiografía, los setenta supusieron un momento de crisis y "disolución", que implicó tanto el cierre -momentáneo o definitivo- de las dos únicas instituciones específicas que tenía la historiografía de la arquitectura -como lo fueron el Instituto de Arte Americano (IAA) y el Instituto Interuniversitario de Historia de la Arquitectura (IIDEHA)-, cuanto una serie de replanteos respecto al objeto y las delimitaciones de la historia de la arquitectura. A esta situación le siguió una relativamente rápida reconstitución, en la cual $S / h$ tuvo un papel central, no sólo porque ofrecía una mira-

Figura 1: Portada de Documentos para una historia de la arquitectura Argentina

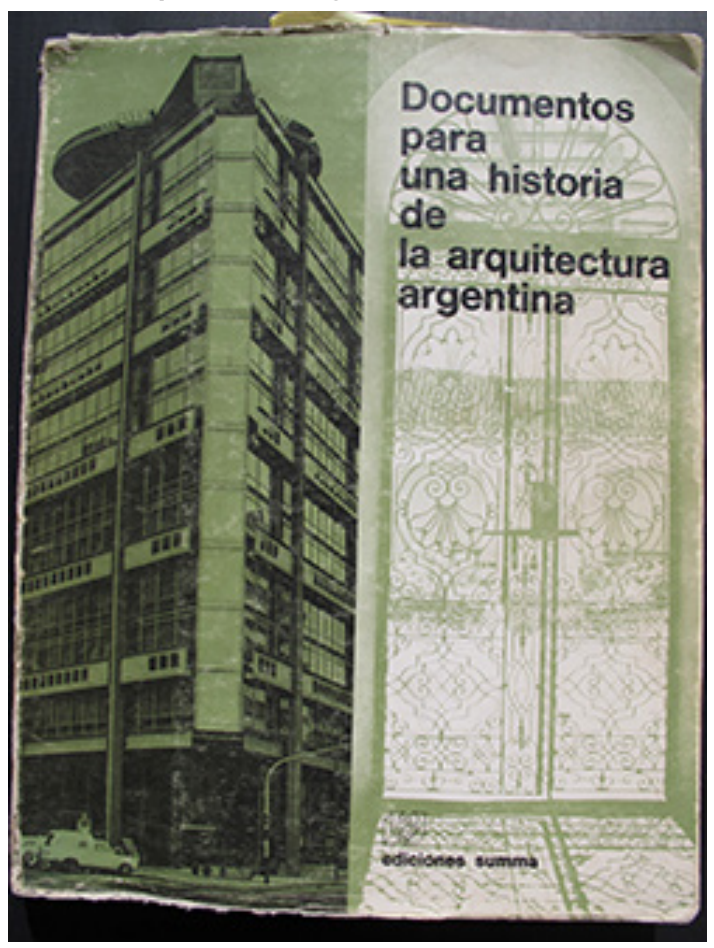

Fuente: Waisman, 1984a 
da integradora de la historia de la arquitectura en el país, no ensayada hasta el momento, sino también porque dinamizó redes y contactos que se prolongaron en el tiempo. Redes y contactos que muestran que, en buena medida, ese proceso de reconstitución provino de espacios provinciales, aún cuando Buenos Aires se mantuviera como el principal escenario de producción historiográfico. Por otro lado, tanto $S / h$ cuanto el libro que se ofrecía como su marco teórico, La estructura histórica del entorno, remiten a un universo referencial que excede a la cultura arquitectónica. Modelos o tradiciones historiográficas, autores, teorías o campos problemáticos -como la semiótica o el estructuralismo- dan cuenta de una serie de préstamos y cruces que son necesarios de reponer en sus marcos de circulación más amplios.

En tal sentido, La estructura histórica del entorno participaba en la revisión de las referencias teóricas de la historiografía de la arquitectura, en la que puede verse un desplazamiento desde la estética hacia las ciencias sociales, que además implicaba una ruptura con las posiciones sostenidas por Enrico Tedeschi, con quien Waisman había compartido numerosos espacios institucionales, como el IIDEHA. En ese libro, Waisman proponían la emergencia de un "nuevo" objeto que, en base a Michel Foucault, Umberto Eco y Reyner Banham, procuraba acercarse a una historia basada en la noción de tipología. Esas lecturas situaban a la autora en el marco más general de la recepción de la semiótica y el estructuralismo que, en el caso de la Argentina de los setenta, se dio en un contexto de radicalización política, del cual Waisman se mantuvo al margen. Pero, a pesar de estos planteos, se observa un desfasaje con el tipo de historiografía ofrecida en $S / h$, en la que prevalece un abordaje tradicional anclado en consideraciones sobre obras ejemplares y enfocada a cuestiones de estilo. Esto se debió a que $S / h$ recuperaba trabajos publicados previamente, realizados por autores que, como Federico Ortiz, Ramón Gutiérrez, Alberto De Paula o Alberto Nicolini, se habían formado en el IAA, caracterizado por su afán documentalista y un modelo historiográfico poco preocupado por las discusiones teóricas. Por otra parte, la aparición de $S / h$ revitalizó las redes y contactos que se habían creado en torno al IIDEHA y el IAA, dando lugar a la creación de nuevos espacios específicos para la historiografía de la arquitectura, como el Instituto Argentino de Investigaciones en Historia de la Arquitectura y el Urbanismo, creado en 1978 en Mar del Plata.

\section{Crisis y disolución en la histo- riografía de la arquitectura}

Como decíamos, hasta la década de 1970 las dos únicas instancias específicas para la historiografía de la arquitectura eran el IAA fundado por
Mario Buschiazzo en 1947 en la UBA y el IIDEHA creado por Tedeschi en 1957 con asiento en Córdoba. Por tanto, para dar cuenta del cuadro de situación en el que se produjo s/h se vuelve necesario señalar, aunque sea brevemente, el itinerario seguido por ambas instituciones. Antes de avanzar, conviene señalar que durante los sesenta ambas instituciones generaron perfiles y circuitos diferenciados. Mientras el IAA se orientaba a la investigación y producción historiográfica, con sede en Buenos Aires y aglutinado en torno a su fundador, Buschiazzo, el IIDEHA se pensó como una red que conectaban diversos centros provinciales -Tucumán, Córdoba, Rosario, Mendoza, Resistencia-, cuyo propósito era la formación y especialización de docentes de historia de la arquitectura a partir de una serie de seminarios internacionales.

EI IAA -y su revista Anales del Instituto de Arte Americano e investigaciones estéticas- fue la primera y principal institución dedicada a la historia de la arquitectura. Un rápido recorrido por los números de los Anales muestra una presencia mayoritaria de temas ligados a la arquitectura coIonial, así como trabajos sobre arte argentino y latinoamericano del mismo periodo. Durante una primera etapa, el IAA se caracterizó por un modelo historiográfico, según indica Graciela Silvestri (2004), en el que se privilegiaba el cruce entre documentalismo y patrimonialismo, entendiendo que las tareas del historiador "serio" eran aquellas que correspondían a las disciplinas auxiliares (cronología, archivística), con una inflexión antiespeculativa y antiintelectual ${ }^{4}$. El afán documentalista y el énfasis metodológico -entendido como crítica documental- los acercaba a la renovación historiográfica emprendida por la "Nueva Escuela Histórica" (NEH) desde la década del veinte, en un intento por institucionalizar y profesionalizar la disciplina (Devoto y Pagano, 2009). Además de una mirada compartida sobre el oficio del historiador, varias figuras ligadas a la NEH, como Guillermo Furlong o Carlos Luque Colombres, participaron regularmente del IAA. A partir de 1955, al tiempo que las temáticas ligadas a la colonia mostraban cierto agotamiento -ya sea porque los principales edificios del periodo ya habían sido relevados o porque estos no podían ofrecer respuestas a una historia entendida operativamente (como guía para la práctica profesional presente)-, el ingreso de una nueva generación de investigadores abrió, se podría decir, una nueva etapa en la que se fueron incorporando nuevas temáticas, como el siglo XIX, la arquitectura rural e industrial y la arquitectura moderna, en un marco más general en el que las formas tradicionales de la historia de la arquitectura como historia del arte comenzaban a entrar en crisis (Silvestri,

4 En líneas generales, sigo los planteos de Silvestri (2004) 
2004). Justamente, fueron algunos de los miembros de esa nueva generación quienes resultaron en los principales colaboradores de $S / h$. Nos referimos a: Alberto de Paula (1936). Egresado de la UBA en 1972, revestía como investigador del IAA desde 1958 y como adjunto de Historia desde 1974. Alberto Nicolini (1931) egresó de la UBA en 1958, aceptando al año siguiente un cargo de profesor titular en la Universidad de Tucumán, donde se radicó definitivamente. Federico Ortiz (1929) egresó de la UBA en 1956, donde luego se desempeñó como titular de Introducción a la Arquitectura y como adjunto de Historia de la Arquitectura. Ramón Gutiérrez (1939) egresó de la UBA en 1963 e inmediatamente ingresó como docente en la Facultad de Arquitectura, incorporándose al IAA. En 1970 -y con 31 años- ya era titular de Historia de la Arquitectura en la Universidad del Noreste.

Ahora bien, la figura central de Buschiazzo y el numeroso cuerpo docente que trabajaba en el IAA determinaron una posición central en el incipiente campo de la historiografía de la arquitectura. Esto permitiría entender por qué se autoexcluyeron del IIDEHA, a pesar de haber participado de la reunión en Tucumán que le dio origen. Efectivamente, sobre la base de una serie de artículos en los que analizaba el estado de las facultades de arquitectura del país (Tedeschi, 1956; 1957), el italiano Enrico Tedeschi ${ }^{5}$ convocó allí a una reunión de profesores de historia de la arquitectura en 1957, en el que se propuso la creación del IIDEHA, siendo elegido él como su primer presidente, quedando Waisman como su secretaria y Córdoba como su sede permanente.

Pero a las diferencias de pesos relativos entre el IAA y el IIDEHA, se puede identificar una diferencia en términos conceptuales. Justamente, en aquella reunión hubo un acuerdo general en la necesidad de superar las visiones positivistas y enciclopedistas por una aproximación crítica, pero en el transcurso de las deliberaciones emergieron dos posturas diferenciadas respecto de cómo entender esa aproximación. El eje del desacuerdo pasaba por la pregunta sobre cómo debía establecerse la relación entre arquitectura y cultura. La postura de Tedeschi, que subsumía la historia de la arquitectura a la historia del arte, era la mayoritaria. La otra postura, la de Buschiazzo y Leopoldo Artucio de Uruguay, sin un planteo del todo preciso, alertaba contra las aproximaciones esteticistas y bregaba por la necesidad de incluir aspectos sociológicos en la comprensión de la obra arquitectónica (UTN, 1957). Según señala Nicolini en un texto retrospectivo, "la nueva generación [la suya], a la que podríamos llamar 'del

$5 \quad$ Tedeschi llegó al país en 1948 para instalarse en Tucumán como profesor de Historia y Teoría de la Arquitectura, en 1956 ingresó como profesor de Teoría en la Universidad de Córdoba.
56', hizo de la preocupación por el 'medio cultural' y sus relaciones sincrónicas con la arquitectura una cuestión explícita y enfática" (Nicolini, 2007: 20) $)^{6}$.

Pero más allá de esta disputa por el sentido de la noción de "crítica" -Tedeschi podía apelar a Croce mientras que Nicolini a un Hauser despojado de toda connotación marxista-, el resultado historiográfico de ambas posturas terminaba siendo el mismo, una historia en el que la arquitectura se explicaba a ella misma. Esto queda más claro cuando se analiza la cuestión del "contexto" al que hace referencia Nicolini. El problema es que sin un planteo teórico definido, las relaciones entre la arquitectura y su "medio cultural" quedan reducidas a que éste aparezca como un trasfondo, como un "otro" ajeno al desarrollo de la arquitectura. Esta cuestión se hace evidente en La arquitectura del liberalismo de Ortiz, en lo que podría considerarse un caso paradigmático de un modelo historiográfico de larga raigambre que, entre otros casos, veremos repetirse en $S / h$. Si, en términos de contenidos, el libro supuso -como señalan Gorelik y Silvestri (1988: 178-179)- la consagración de un cuadro interpretativo en el que los problemas del presente tenían su origen en el esquema importado del liberalismo por parte de las élites del país, lo que nos interesa resaltar es el rol asignado al texto de Abelardo Levaggi -un historiador vinculado a la NEH- que consistía en narrar el contexto sobre el que se desarrollaba la arquitectura. $Y$ aquí hay que notar la distancia entre las apreciaciones de los arquitectos -Ortiz y Juan Mantero- y la de Levaggi. Mientras éste presentaba un análisis del periodo que resultaba en una mirada equidistante respecto a las antinomias que se habían dado entre las visiones liberales y revisionistas sobre la historia argentina, Ortiz y Mantero condenaban in toto a la "arquitectura del liberalismo" por considerarla un error que no debía repetirse. Aunque detrás de esa valoración haya elementos fuertes de la cultura arquitectónica moderna -como analizaremos más adelante-, no deja de ser indicativo de lo complejo que pueden resultar los diálogos entre dos áreas historiográficas, produciendo una suerte de "diálogo de sordos".

Si en el caso de la Arquitectura del liberalismo la arquitectura se independizaba de su contexto, en la producción del IIDEHA el contexto -por lo menos en su consideración social y cultural- no era tenido en cuenta. Los pocos libros publicados consistían en relevamientos y análisis de iglesias y conventos de la época colonial ${ }^{7}$. Por

$6 \quad$ Ahí mismo señalaba que la preocupación por las relaciones entre la arquitectura y su contexto encontraban su fundamento teórico en las obras de Erwin $\mathrm{Pa}$ nofsky y de Arnold Hauser.

7 Tedeschi, E. et al: La catedral de Puno, Córdoba, IIDEHA, 1963; Roca, J.: Las Teresas. Iglesia y 
tanto, más allá de acentos y discrepancias no diferían demasiado de lo producido en el IAA. El IIDEHA resultó más importante en términos de circulación de ideas, por medio de sus boletines -que estaban dedicados, mayoritariamente, a la crítica bibliográfica, mostrando un amplio manejo de las novedades en inglés, francés, italiano y alemán-, pero principalmente por la organización de una serie de seminarios internacionales que fueron dictados, entre 1960 y 1970, por Nikolaus Pevsner, Giulio Argan, Chueca Goitia, Vicent Scully, Reyner Banham y Umberto Eco. Pensados como espacios de actualización de las perspectivas de abordajes historiográficos, cada seminario resultó en un evento en sí mismo que tuvo repercusiones en ámbitos más amplios que el de la historia. Mientras los cuatro primeros respondían a la postura de Tedeschi ${ }^{8}$, los últimos dos -realizados bajo la presidencia de Waisman- son indicadores del creciente interés en las ciencias sociales -cuyo impacto en La estructura histórica del entorno analizaremos más adelante-.

Ahora bien, la crisis de las formas tradicionales de la historia de la arquitectura y el creciente acercamiento al discurso de las ciencias sociales se dio en el contexto de una progresiva radicalización social y política en la Argentina de finales de los sesenta y principio de los setenta. Este afectó con particular fuerza a las facultades de arquitectura del país, produciendo algunas de las experiencias más radicales en las universidades argentinas. Por caso, en septiembre de 1970 se puso en funcionamiento el Taller Total en Córdoba, al año siguiente se extendió a Rosario, mientras que en Buenos Aires aparecieron los Talleres Nacionales y Populares (TANAPO) en 1974. En el clima de politización que se vivía en las facultades, el recurso a las ciencias sociales -particularmente la sociología y la semiótica- contribuyó a repensar el compromiso social de la arquitectura, el lugar del usuario en el proceso de diseño o la función del arquitecto en la construcción del hábitat, por nombrar algunas cuestiones. En este marco es que se produjo el cierre -temporal o definitivo- del IAA y del IIDEHA. En un sentido literal, el cierre supuso la "disolución" de estas instituciones. En un sentido metafórico, los debates que ahí se dieron parecían indicar que la historia era "disuelta" en un conjunto mayor de problemáticas. De forma explícita en el Taller Total de Córdoba, de forma más difusa en el caso del IAA. Si bien en ninguno de los dos casos se realizó una producción que diera cuenta de esta situación, no deja de ser indicativo del estado de

convento de las Carmelitas descalzas de Santa Teresa, Córdoba, IIDEHA, 1965; Arribillaga, A. et al: Bom Jesús de Matozinho, Resistencia, IIDEHA, FIVP, 1971.

8 Sobre las posturas historiográficas de Tedeschi y su impacto en la cultura arquitectónica argentina, véase Malecki (2013). redefiniciones por la que atravesaba la historia de la arquitectura.

Con la muerte de Buschiazzo en 1970, el IAA entró en una suerte de crisis que, unida a la situación de creciente politización en la facultad, llevó a que cerrara por un tiempo prolongado, incluyendo la suspensión de los Anales. No contamos con un estudio detallado que nos permita precisar qué pasó con el Instituto -incluso con la facultad- en los tempranos setenta, aunque con la información disponible podemos aventurar algunas hipótesis. Por un lado, se acentuó la dispersión de los miembros del IAA que había comenzado con las renuncias de profesores en respuesta a las intervenciones a las universidades en 1966. Por caso, Gutiérrez se trasladó a Resistencia en 1970, al igual que Ricardo Alexander. El propio Instituto -junto a su biblioteca y archivo- fue trasladado a la nueva sede de la Facultad en Ciudad Universitaria entre 1971 y 1972, dificultando su funcionamiento. Además, su nuevo director, Jorge Gazaneo, fue designado coordinador de la comisión que debía entender respecto a la restauración y uso futuro de la "Manzana de las luces". En lo sucesivo, parece que Gazaneo priorizó el trabajo de restauración y conservación patrimonial, articulando actividades con ICOMOS. En 1973 Gazaneo fue separado de su cargo, siendo restituido recién en $1975^{\circ}$.

Por otro lado, hacia finales de los sesenta es posible rastrear una serie de textos producidos en el marco del IAA en los que se comenzó a problematizar las formas tradicionales de la historia de la arquitectura, ya sea por la incorporación de nuevo objetos, como en el caso de Gazaneo y Mabel Scarone, o por la reformulación de los presupuestos que se habían manejado respecto a la arquitectura colonial. Así, por ejemplo, Buschiazzo proponía revisar algunos de los supuestos que habían motivado los principales enfoques sobre la arquitectura colonial. El texto en sí no avanzaba con una programática renovadora, pero era indicador de un estado de incomodidad respecto al estado actual de las investigaciones: "una vez más, insisto en que no estoy negando posturas mías pretéritas, sino tan solo repreguntando, interrogando, afinando la apreciación para no dejarme llevar por entusiasmos que todavía siento, pero que deseo frenar con el raciocinio" (Buschiazzo, 1969: 88). Más decidido era el planteo de Damián Bayón que, de forma provocativa, sostenía que "en Sudamérica el arte colonial cuenta apenas con un puñado de obras maestras", para

9 Hemos extraído la información respecto al IAA y de Gazaneo de los artículos publicados en Anales, número 31-32 de 1996-1997 dedicado al veinticincoavo aniversario de la muerte de Buschiazzo, sobre todo los textos de de Paula (1997) y de Pando (1997). Cabe destacar que la información se presenta confusa y poco clara. 
señalar la necesidad de restituir los fenómenos artísticos a "la más vasta Historia General de la cultural". Para ello, decía, había que alejarse de la "historia-monumento", prescindir de la idea de "escuelas" y "estilos" para trabajar con "tipologías" y "series" (Bayón, 1970). Aún más contundente, José Xavier Martini sostenía que, luego de un primer momento romántico-nacionalista y de otro riguroso documentalista en la historia de la colonia, había que avanzar en un tercero de valoración global y crítico. Según indicaba, "el punto de partida para definir el modelo conceptual de la arquitectura colonial argentina reside en sustraerla del ámbito de las bellas artes", para aclarar que "su motivación principal [la de la arquitectura colonial] no es estética; su finalidad no es la creación de formas. Los productos de la arquitectura colonial son más artefactos que obras de arte" (Martini, 1971: 13-14). Si estos trabajos muestran un intento de redefinir una de las temáticas centrales del trabajo del IAA, la inclusión de nuevos objetos desestabilizaba los cánones de la historiografía tradicional. Por caso, Gazaneo y Scarone habían publicado un conjunto de trabajos sobre arquitectura rural e industrial en los que llamaban la atención, por primera vez, sobre el rol de la tecnología de la revolución industrial en la conformación del hábitat urbano y rural ${ }^{10}$. El enfocarse en un conjunto de objetos que habían permanecido por fuera de aquellos que se consideraban legítimos para la historia de la arquitectura, supuso un fuerte desplazamiento respecto a las formas tradicionales, que se basaban en la distinción entre "construcción" y "obra de arquitectura" para establecer lo que era propia de ella y lo que no.

No es de extrañar, entonces, que la nueva etapa que parecía abrirse en el número 24 de Anales se retomaran muchas de aquellas cuestiones. Según apuntaba Gazaneo (1970: s/p) en la presentación: "nuestra interpretación se ocupará menos de la 'arquitectura' y del 'arte' como entes autónomos, y profundizará en aquellas manifestaciones que definen el entorno construido del hombre -se consideren las mismas 'arte' o no". Los problemas en el IAA y la interrupción de los Anales impidieron proseguir en esa dirección. Esta situación de crisis era compartida, aunque con otros acentos, en el Taller Total e, incluso, por Marina Waisman en la Estructura histórica del entorno.

El caso de Córdoba difería sustancialmente del de Buenos Aires. No sólo porque allí la crisis excedía al IIDEHA y al tema de la historia para abarcar al conjunto de la facultad, sino porque el nivel de radicalidad fue mayor que en Buenos $\mathrm{Ai}$ res. Radicalización que llevó a una reformulación

10 Tres asentamientos rurales (1965), La arquitectura de la revolución industrial de la Argentina (1966) y Revolución industrial y equipamiento urbano (1969). integral del plan de estudios y del funcionamiento de la facultad. Además, la estrecha relación entre Waisman y Tedeschi junto a la posición institucional que ambos tuvieron en Córdoba (Waisman fue electa vicedecana en abril de 1970 y Tedeschi designado como uno de los directores de los Talleres Verticales que finalmente no llegaron a implementarse) determinaron que, en la crisis institucional que se vivió en la FAU que condujo al Taller Total en 1970, ambos quedaran asociados a una forma de ver y entender a la arquitectura contra la cual el Taller Total se oponía (Malecki, 2016). En el clima de conflictividad que se vivió allí, Waisman optó por un año sabático en 1971, durante el cual escribió La estructura histórica. A su regreso siguieron los enfrentamientos, lo que determinó su renuncia a la universidad en 1973.

De las diversas cuestiones que involucraron la compleja experiencia del Taller Total, nos interesa detenernos, aunque sea brevemente, en los debates en torno a la noción de "hábitat". Con el nuevo Plan de Estudios, las antiguas materias de Historia de la Arquitectura fueron subsumidas en la sub-área de "Historia crítica del hábitat". La nueva denominación implicaba no sólo un cambio de nombre, sino un desplazamiento y una suerte de "disolución" del objeto de la historia de la arquitectura en la del hábitat, que además se ofrecía como un aporte disciplinar específico al contexto de radicalización política. Estos debates, que provenían de una serie de reformulaciones al interior de la cultura arquitectónica ${ }^{11}$ pero que -en el caso del Taller Total- tomaban muchas de sus referencias de las ciencias sociales, suponían considerar a la arquitectura como una variable igual de importante que otras -como las sociales, económicas o simbólicas- en la construcción del hábitat. Y era esta misma categoría la que se convertía en una noción total, en tanto una "totalidad social" que se oponía, como veremos más adelante, a la idea de "entorno" como categoría parcial. De las discusiones allí sostenidas, quisiéramos destacar la idea de que el espacio -y con él el diseño arquitectónico- no podía ser reducido a su condición física. Justamente, las distintas intervenciones coincidían en afirmar que el hábitat era, antes que nada, un hecho cultural y por tanto, se trataba de una construcción social, según indicaba Iván Baigorria. En una línea similar, Liliana Rainis sostenía que la arquitectura contenía "modos de vida", mientras que Mario Corea proponía entender al urbanismo como una

11 Michel Ecochard fue uno de los primeros en introducir la noción de hábitat en sus trabajos realizados en el protectorado francés de Marruecos en los cincuenta, retomada, en parte, por Le Corbusier en su intento de sustituir la "Carta de Atenas" por la "Carta de Hábitat". Con la exposición "Hábitat 67" en Montreal, el tema cobró fuerza en las agendas públicas, al punto que la ONU organizó una conferencia internacional sobre Hábitat en Vancouver en 1976. Ver, Malecki, 2014 
praxis social y al arquitecto como un intelectual. Estas consideraciones implicaban un giro de los arquitectos hacia unas ciencias sociales que estaban en un intenso diálogo con una historiografía que, para la misma época, también recurría a la antropología y la sociología para renovar sus indagaciones, como la ensayada por la Escuela de los Annales -particularmente por Braudel- y la de corte marxista. Este giro estuvo acompañado, además, por la incorporación de un grupo de cientistas sociales que plantearon con mayor precisión algunas cuestiones referidas a los procesos de urbanización, en los que se volvía a criticar la reducción del espacio a un hecho físico y proponían, en contraposición, una "dialéctica del espacio y una dialéctica de la duración"12.

\section{La estructura histórica del en- torno}

Como señalábamos al comienzo, en $L a$ estructura histórica del entorno Waisman no sólo se posicionaba ante la crisis por la que estaba pasando la arquitectura, sino que también puede leerse como una respuestas a los debates sobre el hábitat en el Taller Total, al tiempo que marcaba una serie de rupturas respecto a los marcos teóricos que había difundido Tedeschi. En tal sentido, introducía una serie de autores y temáticas que si eran ajenas a las referencias de Tedeschi, resultaban parcialmente compartidas con el Taller Total pero con un sentido completamente diferente. Ya el título era indicativo del doble desplazamiento que operaba Waisman: si la noción de entorno se presentaba como una alternativa a la de hábitat -en tanto objeto de las "ciencias del diseño"-, la de estructura descentraba la noción de "sujeto creador" de Tedeschi a la vez que la colocaba en los debates del estructuralismo y la semiótica. Para Waisman, entonces, la historia de la arquitectura ya no podía pasar por el análisis de la personalidad creativa de los arquitectos, sino que debía enfocar sus mejores instrumentos de análisis a los problemas estructurales y tipológicos que se derivaban de un objeto arquitectónico entendido como una construcción histórica mutable, lo cual suponía una constante redefinición de sus límites.

Para ello, las nociones foucaultianas de "estructura" y de "a priori histórico" le permitían descentrar de una perspectiva estética el problema de la forma, al mismo tiempo que reclamar la autonomía de la historia y proponer la construcción de su propio "objeto histórico". Lo que había que discutir, decía Waisman, eran las ideologías arquitectónicas, ya que no se podía confundirlas, sin más, con las ideologías políticas. Porque si en el Taller Total se entendía a la ideología en su acepción marxista de "falsa conciencia" -Mario

12 He trabajado estos temas más en extenso en Malecki (2014), sobre todo en el capítulo 5.
Corea sostenía que el carácter ideológico del diseño ocultaba una estrategia de clase-, para Waisman significaba el particular "recorte" que realizaba el pensamiento sobre el mundo. Esto le permitía reconocer las mediaciones entre arquitectura y política, pero en vez de llevarla a una reconsideración de esas relaciones, terminaba reafirmando la autonomía de la arquitectura.

Según Waisman (1985: 27), la crisis por la que estaba atravesando la arquitectura la llevaba a plantear "la delimitación de un nuevo territorio": "¿Cómo podría la historia ejercer su función crítica cuando su objeto mismo ha dejado de existir, presuntivamente, al transformarse de tal modo que en definitiva parece haber sido sustituido por otro objeto?". Para la autora, la respuesta a esta pregunta era la negación de la pregunta misma porque ella asumía que el objeto arquitectura "conserva un significado constante". En cambio, recurría a "las reglas para la formación de los objetos" de Foucault para indicar tres instancias que han hecho a la construcción histórica del objeto arquitectónico: "la diferenciación del objeto arquitectónico respecto de otros objetos construidos"; la vigencia de un "sistema de diferenciación y clasificación", que es la puesta en práctica de una escala de valores -una ideología-; las diferentes "instituciones" por medio de las cuales operan los sistemas de selección (Waisman, 1985: 28-40).

Por otro lado, la noción de entorno era construida a partir de Banham y Eco. En el libro de Waisman el Banham que aparecía es el de The Architecture of the Well-Tempered Enviroment, en el que se planteaban las relaciones entre tipología y entorno. Eco le permitía a Waisman introducir las consideraciones semiológicas a partir de las cuales la arquitectura se podía pensar como un "texto" abierto, como un sistema de codificaciones que se establecen entre lo arquitectónico y su exterior. Si, en las consideraciones del Taller Total sobre el hábitat, la noción de arquitectura entendida como proceso creativo tendía a diluirse en un conjunto de variables que la excedían y la comprendían, Waisman intentaría reafirmar la especificidad del hecho arquitectónico recurriendo a la noción de tipología. Así, lo que estaba en el centro del análisis de Waisman eran las "unidades culturales", que suponían unos sistemas de valores y de pensamientos que le daban consistencia, pero que se recostaban sobre una idea de entorno entendido como "un conjunto general de límites indefinibles" en donde las "articulaciones interiores result[a]n asimismo imposibles de delimitar con precisión" (Waismanm 1985: 48). Para poder abordar esas unidades, Waisman sostenía que había que dejar provisoriamente de lado la individualidad de obras y autores -donde sitúa el nivel de la "parole", en analogía con la lingüísticapara buscar establecer series y tipos (Waisman, 1985: 60-61). Con esto introducía la cuestión ti- 
pológica como elemento central para la historia de la arquitectura, cuya principal referencia era el texto de Argan de la Enciclopedia Universale dell'Arte, luego incluido en Progetto e destino, de 1965.

Waisman reconocía tipologías de tipo "estructural", "formal", "funcional" y de relaciones entre edificios y entorno. Para ella, era a nivel de las tipologías formales donde se podía plantear el problema de la "interpretación" al que daba lugar la semiología de Eco, ya que una tipología siempre implicaba una relación con el entorno físico que, en el texto de Waisman (1985: 86-96), era asimilado al de entorno cultural. Pero como no hay una correspondencia directa entre tipo y entorno, el tipo formal suponía, para Waisman, un "recorte", por tanto, una ideología. Según sus palabras: "el acto de formar es al mismo tiempo el acto de poner en obra una ideología. Entonces, la forma arquitectónica, al significarse a ella misma, significa al mismo tiempo una ideología arquitectónica" (Waisman, 1985: 91) ${ }^{13}$. Pero si la forma arquitectónica se significaba a ella misma, lo que determinaba la ideología era la forma y no la relación entre los componentes ideológicos, lo que llevaba a un planteo tautológico y, por cierto, muy poco "estructuralista" si tenemos en cuenta que éstos suponen establecer equivalencias formales -o isomórficas- a partir de analizar las relaciones que se establecen entre los elementos que conforman una estructura y nunca un elemento en sí mismo.

Ahora bien, si las principales referencias teóricas de La estructura histórica eran Foucault, Eco y Banham, cabría preguntarse por los marcos más amplios en los que circularon esos autores en Argentina. Los nombres de Foucault y de Levi-Strauss -a quien cita reiteradamente- son los que la colocan en un lugar excéntrico, no sólo para la arquitectura, sino con relación a la recepción argentina del estructuralismo francés. Efectivamente, los años sesenta estuvieron marcados por el auge de los discursos marxistas y estructuralistas, con un importante punto de cruce en la obra de Louis Althusser (Tarcus, 1999). La difusión de su obra encontró diversos medios. Uno de ellos se dio a través de la renovación del pensamiento sociológico llevada a cabo por Eliseo Verón -junto a Emilio de Ipola y Ernesto Laclau, entre otros-, quien además se constituyó en una de las principales referencias de la semiótica en la Argentina. Otro de esos canales fue la revista Los Libros, fundada por Héctor Schmucler en 1969, que venía de estudiar con Roland Barthes en París. Adoptando el modelo de la La Quinzaine Littèraire, la revista buscaba incidir sobre la coyuntura por medio de la crítica de libros, poniendo en circulación nuevas perspectiva de análisis, principalmente las ligadas al estructuralismo

\footnotetext{
13 Destacado en el original
}

francés. Con el tiempo, se convirtió en uno de los principales medios de expresión de un sector de la izquierda intelectual radicalizada.

Así, una de las vías de recepción de Foucault en la Argentina fue a través de los comentarios elogiosos que había recibido por parte de Althusser, colocándolo como parte del "frente estructuralista", mientras que las otras recepciones fueron en sede psicoanalítica -como en los trabajos de José Bleger- y filosófica, principalmente en su vertiente sartreana existencialista (Canavese, 2015). De tal forma, para principio de los setenta sus principales libros ya habían sido traducidos, siendo su figura medianamente conocida (aunque no con el impacto que tuvo posteriormente). Este breve recorrido nos permite preguntarnos cómo llegó Waisman a Foucault. La hipótesis más probable es que lo haya hecho a través de su marido, Abraham Waisman, docente de filosofía en la Facultad de Filosofía y Humanidades de Córdoba, en donde había coincidido en los sesenta con Schmucler y Oscar Del Barco, aunque en grupos políticos opuestos y hasta enfrentados $^{14}$. Abraham Waisman trabajaba temas de teoría y filosofía de la historia, por lo que no sería raro que se haya topado con el nombre de Foucault, aunque su orientación estuviera más cerca de la filosofía especulativa. Tal vez esto explique que el Foucault de Marina Waisman sea el de la Arqueología del saber y no el de Las palabras y las cosas. Es decir, el Foucault metodólogo y no el histórico-filosófico. Por ello podía recurrir a los conceptos de la Arqueología pero desentenderse de las hipótesis históricas que planteaba en torno a las discontinuidades discursivas del "saber" en Las Palabras y las cosas. Si Waisman supuso una de las primeras entradas de Foucault en la cultura arquitectónica -presencia que no tuvo continuidad en sus trabajos-, fue recién con el "retorno democrático" cuando el nombre de Foucault ganó espacio en los debates arquitectónicos -proporcionalmente al espacio que había ganado en las agendas públicas-.

A diferencia del conocimiento parcial que se tenía de Foucault, el nombre de Eco tenía una presencia importante en una serie de debates que iban de la semiótica a la crítica cultural ${ }^{15}$. Son pocos los estudios sobre la presencia de Eco en la Argentina o sobre el desarrollo de la semiótica, por lo que no es posible trazar con precisión las

14 Oscar del Barco, era docente de la Escuela de Historia, y Schmucler lo era de la Escuela de Letras. Ambos habían participado de la revista animada por José María Aricó, Pasado y Presente y en Los libros. Aunque no contamos con una historia de la FFyH, se podría decir que Waisman pertenecía a los sectores liberales de la Facultad.

15 Sus principales libros, Obra abierta e Integrados y apocalípticos, habían sido traducidos en 1965 y 1968, respectivamente. 
formas de su recepción en la Argentina ${ }^{16}$. Sin embargo, en función de nuestro tema quisiéramos mencionar, al menos, tres vías. Una de ellas nos sitúa en la problemática del "escritor revolucionario" y de la serie de debates que se dieron en torno al "realismo", en tanto tópico que permitía problematizar las relaciones entre literatura y sociedad, estética y política, y para las cuales fueron centrales la recepción de las neovanguardias francesas de Tel Quel e italianas del Gruppo 63 -al que pertenecía Eco, junto a Edoardo Sanguineti y otros- en la revista Los Libros ${ }^{17}$. Otra de las vías fue por medio de la cátedra de Semiótica de la Arquitectura en la UBA, cuyo titular era César Janello y en donde trabajaban Mario Gandelsonas y Diana Agrest. La de Waisman -y en alguna medida de Summa- podría ser una tercera vía de entrada de Eco. Fue justamente Waisman la que organizó la primera visita de Eco a la Argentina para que diera un seminario en el marco del IIDEHA, realizado en La Plata en abril de 1970 por el conflictivo clima que se vivía en Córdoba ${ }^{18}$.

El Eco que le había interesado a Waisman era el que había intentado un cruce entre semiótica y arquitectura en la Estructura ausente de 1968, publicado parcialmente en los Cuadernos Summa-Nueva Visión ${ }^{19}$. Para Waisman, Eco era una puerta de entrada al cruce entre semiología y diseño que se estaban dando en Italia y que, en el marco del surgimiento de las neovanguardias, había despertado el interés internacional. Así parecería inferirse del hecho de que en el número que Summa le dedica a la exposición Italy: The New Domestic Landscape -organizada por Emilio Ambasz en el MoMa de Nueva York en 1972-, se incluyera una serie de textos de Eco -que no eran parte de la muestra- y se omitieran los textos mucho más críticos de Tafuri que sí estaban incluidos en el catálogo. Si el primero señalaba alegremente las contradicciones a las que se enfrentaban los diseñadores radicales -particularmente Archizoom, Superstudio, Gruppo 9999- al decir que "proyectan y diseñan su protesta contra el universo del diseño industrial adaptado a las exigencias de la sociedad de consumo" (Eco, 1972: 58), el segundo mostraba que la "revuelta de los objetos" de los diseñadores italianos, bajo el piso común del estructuralismo y las teorías semiológicas de la comunicación, ejemplificaba la ratio por la cual la utopía tecnológica del diseño ocultaba su propia contribución a la reconfiguración del capitalismo (Tafuri, 1972). Si Tafuri repre-

16 El único trabajo que hemos podido encontrar sobre el tema es el de Raversa (2010).

17 Ver García (2011).

18 Luego del seminario de La Plata, el IIDEHA no tuvo más actividad pública. Para una historia parcial sobre el IIDEHA, véase Malecki (2013). También puede consultarse Gutiérrez, y Paterlini (2007).

19 Cuadernos Summa-Nueva Visión, N N 31/32 "Comunicación", julio de 1969. sentaba la posición más crítica y políticamente comprometida, la de Eco resultaba más ambigua y despreocupada respecto a sus implicancias y, por tanto, más fácil de asimilar por lectores interesados en el hecho del diseño en sí. Además del prestigio de Eco, posiblemente haya sido esta posición moderada la que le interesaba a Waisman para invitarlo a dar el seminario del IIDEHA, ya que le permitía un juego controlado respecto a los saberes que estaban cuestionando los límites de la arquitectura. Así parecía sugerirlo cuando justificaba la invitación de Eco al seminario: "por esa necesidad urgente que tiene hoy todo arquitecto que se respete, de tratar de salirse del campo de la arquitectura para reconsiderar su propia acción desde nuevos puntos de vista" (Waisman, 1970: 77).

Banham, por su parte, ya era una figura conocida para principio de los setenta, no sólo por su relación con Archigram y la cultura pop inglesa -a quienes había apoyado en su carácter de editor de Architectural Review-, sino por su primer libro, Teoría y diseño arquitectónico en la primera era de la máquina, producto de su tesis doctoral desarrollada bajo la dirección de Pevsner, y publicada en español por la Editorial Infinito en 1965. Allí Banham intentaba desmontar la historiografía del "movimiento moderno", sobre la base de señalar no sólo algunas de las continuidades con la arquitectura academicista -particularmente las de Le Corbusier con Choisy-, sino también indicar que para el propio desarrollo de la arquitectura moderna fue más importante la construcción simbólica de una imagen -emparentada a la estética de la máquina gracias a la difusión de las imágenes del futurismo italiano- más que el resultado del desarrollo de la noción de "función" (Vidler, 2008). Invitado a Córdoba para participar de uno de los seminario del IIDEHA en 1968, Banham presentó allí su trabajo en curso sobre las relaciones entre tecnología, ambiente y arquitectura, publicado en inglés al año siguiente como The Architecture of the Well-Tempered Enviroment. Como bien señala Claudia Shmidt (2016), la visita de Banham a Córdoba se produjo en un momento en el que todavía no estaba claramente diferenciado los contornos entre los conceptos de ambiente, entorno y hábitat. $Y$ resulta elocuente de ello que Waisman recurriera a la noción de "ambiente" menos en términos de "control ambiental" -tal como lo proponía Banham- que como sinónimo de entorno.

\section{IV summa/historia}

Disueltos los dos centros que aglutinaban a los historiadores de la arquitectura en los tempranos setenta, tensionada por el contexto de radicalización y politización, la historia parecía cambiar la matriz desde la que se la miraba y estudiaba. La aparición de S/h en 1974 permitió una rápida 
reconstitución del campo de la historiografía, en el que algunos de los reposicionamientos previos -las relecturas de la arquitectura colonial, la ampliación de la noción de arquitectura a la de entorno o la incorporación de la arquitectura rural e industrial- eran incluidos, pero cuya innovación quedaba desdibujados en un esquema que tendía a reproducir las formas tradicionales de ver la historia, debido a que s/h ponía en circulación, principalmente, trabajos realizados durante los sesenta. Pero deberíamos precisar esta afirmación: esos trabajos corresponden, en general, a las introducciones a cada capítulo, mientras que buena parte de las entradas fueron realizadas específicamente para $S / h$. Hasta donde hemos podido averiguar, Waisman fue responsable de la iniciativa y llevó adelante el armado de $S / h^{20}$. Aunque más significativo fue que $S / h$ coincidió con un giro hacia las temáticas de la preservación y el patrimonio en Summa. Posiblemente parte de ese giro se debiera a la presencia de Waisman en la revista, de la que era colaboradora permanente desde 1972. A lo que deberíamos sumar la incorporación, hacia mediados de la década, de Julio Cacciatore y posteriormente de Alberto Petrina. Quienes, además de contribuir con temas de historia, patrimonio y conservación, promovieron en los ochenta un reposicionamiento de la revista hacia perspectivas latinoamericanistas -por caso, a partir de 1985 Summa se convirtió en uno de los principales difusores de los debates regionalistas-. Como señal de aquel giro, el primer suplemento de $s / h$ apareció en el número siguiente al que Summa le dedicó, por primera vez, al tema de patrimonio arquitectónico, cuya nota de apertura era de Waisman ${ }^{21}$. Temática que adquirió una presencia cada vez mayor en la revista: por ejemplo, entre julio de 1977 y agosto de 1978 Summa lanzó una campaña para salvar el patrimonio arquitectónico del país, en el que invitaban a los lectores (bajo el lema "la historia de una ciudad muere con sus edificios") a que mandaran fotos e informaciones de edificios históricos. Aunque el alcance se haya pretendido nacional, seguramente el motivo inmediato que animaba la campaña era la propuesta de un sis-

20 Hasta el momento, no ha sido posible dar con los archivos personales de Waisman o los de Summa, por lo que hay muchos detalles de la gestación de $s / h$ que no hemos podido aclarar. Según nos cuenta $\mathrm{Ni}$ colini, la iniciativa correspondió íntegramente a Waisman, siendo ella la que elegía a los autores. No hubo, al parecer, tampoco reuniones para discutir los diferentes aportes (Comunicación con el autor, Tucumán, $30 / 1 / 2017)$. Es de suponer, teniendo en cuenta la periodicidad mensual con que salían los fascículos y que no siguieron un orden cronológico de publicación, que se iban armando para la ocasión, en función del material e información previamente disponible.

21 Summa, n77, 1974, dedicado al tema "revitalización de los centros históricos". tema de autopistas en Buenos Aires que impulsaba el Intendente Cacciatore, el cual implicaba demoler amplias zonas de la ciudad.

Lo que sí ponía en evidencia $S / h$ era la confluencia de las redes que se habían articulado en torno al IAA y al IIDEHA, mostrando, además, cierto reacomodamiento geográfico de sus principales referentes. De tal forma, el impulso a la reconstitución del campo provino, principalmente, de una serie de espacios provinciales. Alejada Waisman de la Universidad Nacional de Córdoba, recaló en la Universidad Católica en donde comenzó a funcionar en 1974, bajo su dirección, el primer curso de posgrado en patrimonio y preservación arquitectónica del país. Como ya señalamos, Gutiérrez y Alexander se habían trasladado a Resistencia. Allí, luego de una reorganización del Departamento de Historia de la Arquitectura en 1971, comenzaron a publicar Documentos de Arquitectura Nacional (DAN, luego reconvertida en Documentos de Arquitectura Nacional y Americana, $D A N A$ ) que sustituyó el espacio que había dejado Anales -el afán documentalista, señalado en el propio título de la revista, la emparentaba con esta última-. A lo que debemos sumarle la presencia de Nicolini en Tucumán.

Dicho esto, ahora podemos avanzar con el análisis respecto a algunos de los contenidos de $S / h$. Si uno la lee de corrido se encontrará con un trabajo heterogéneo, que contiene diferentes posicionamientos y apreciaciones respecto a los capítulos de la historia de la arquitectura en Argentina. Si bien esas diferencias no llegan a marcar una oposición, en tanto no logran desarticular el marco referencial que las sostiene, dan cuenta de algunas revisiones que iban a cobrar forma más adelante -por ejemplo respecto al liberalismo y al peronismo-. También debe marcarse la trayectoria dispar de muchos de los colaboradores de $S / h$, alguno de ellos recién egresados o todavía estudiantes ${ }^{22}$. Por otro lado, hay que señalar la distancia, en muchos casos, entre lo que se muestra -en una publicación en el que las imágenes tienen un lugar central- y lo que se dice. Por ello es difícil proponer una consideración general. Sin embargo, se pueden hacer algunos comentarios globales. En primer lugar, la periodización propuesta no respondía a consideraciones internas a la cultura arquitectónica, sino que se asentaba sobre hechos políticos, reproduciendo las periodizaciones de la historiografía general. Una excepción parcial es el "Periodo de integración nacional (1914-1943)" que aúna dos momentos que suelen analizarse por separados

22 Tal vez el menor de ellos haya sido Daniel Schávelzon, egresado de la UBA en 1975, pero dentro del grupo de recién recibidos debemos incluir a Olga Paterlini -egresada en 1971- y a Alberto Petrina, entre otros. Celia Romaña y Ricardo Wagner eran estudiantes. 
a partir del año bisagra de 1930. Una posible explicación sería que esa fue la forma de combinar la persistencia del eclecticismo con la emergencia de la arquitectura moderna. Esto nos lleva al segundo punto: a pesar de la insistencia de Waisman sobre una aproximación tipológica, $S / h$ se articula mayormente en torno a la consideración de estilos. En realidad, la cuestión de los estilos estructura las introducciones generales de cada capítulo, a lo que le siguen diversas entradas que intentan abordar algunas cuestiones tipológicas. Justamente en esas entradas es posible ver los aportes más innovadores de $s / h$, como los trabajos sobre la "casa cajón", la "vivienda no profesional" -las casas en la Boca-, "los poblados de la industria azucarera", la "arquitectura industrial" o "la infraestructura técnica y profesional en provincias". Podría mencionarse, además, que, por primera vez, se incluyó en un libro de historia de la arquitectura trabajos de historia urbana. Aún así, el evidente desfasaje entre la propuesta general y el resultado es señalado por Waisman (1984b: 8) al reconocer que "la idea de una aproximación tipológica, (...) debió extenderse desde las tipologías edilicias hasta las estilísticas", desvirtuando la innovación que suponía el uso de la noción de "tipo". En tercer lugar, como correlato de una red provincial, $S / h$ procuraba avanzar en una historia de la arquitectura que no estuviera centrada en Buenos Aires. El contraste es notable si la comparamos con ejemplos tan dispares como la Arquitectura en la Argentina: 1810-1930 de Buschiazzo, La arquitectura del liberalismo de Ortiz o la Breve historia de la arquitectura argentina de Jorge Glusberg. Todas ellas tienen en común que, a pesar de remitir a un escenario nacional, centran sus indagaciones en Buenos Aires. A pesar de este loable esfuerzo, los autores no eran conscientes que una mera sumatoria de partes no altera el todo. Dicho de otra forma, el agregado de casos no llevaba necesariamente a modificar la apreciación del conjunto, en tanto no se problematizaba las relaciones entre lo local y lo nacional. Justamente, mientras los estudios de casos no se propongan como parte de problemáticas mayores es poco lo que pueden aportar a una reconsideración de los procesos entendidos en un marco realmente nacional.

Como señalamos al comienzo, $S / h$ condensaba una serie de operaciones historiográficas que dan cuenta del estado del arte del momento, así como de una serie de sensibilidades de la época. Nos detendremos en algunas de ellas, como en la noción de "transculturización", en la apreciación sobre el "eclecticismo" y el "neocolonial" y en la lectura sobre el peronismo. Teniendo en cuenta que $S / h$ se construyó en base a trabajos realizados previamente, procuramos remitirnos a ellos para dar cuenta de sus fuentes.

Empecemos, entonces, por el concepto menos ligado a la arquitectura, el de "transculturización".
Originalmente formulado por el escritor cubano Fernando Ortiz en su libro contrapunteo cubano del tabaco y el azúcar de 1940, el concepto pretendía discutir la noción de "aculturización", al proponer una mirada no esencialista sobre los procesos de transmisión cultural. Aunque recién en los setenta se expandió su uso a otros dominios que el de la antropología, principalmente gracias al trabajo de Ángel Rama, "Los procesos de transculturización en la narrativa latinoamericana" (1974), republicado en Transculturización narrativa en América Latina (1984), con gran impacto en los estudios literarios y luego, a partir de los ochenta, en los estudios culturales. Ajeno a este universo de referencias, la noción ingresó al discurso arquitectónico despojado de toda reflexión teórica. Como señala Felipe Hernández, mientras que en otras disciplinas el concepto de transculturización ha servido para dar cuenta de las dinámicas de interacción social, cultural y artística, en la historiografía de la arquitectura, por el contrario, su uso resultó en una "una visión reductiva de la arquitectura latinoamericana" que, en vez de conectar la arquitectura con procesos sociales y culturales más amplios, sólo apuntaba a "descubrir las transformaciones formales que ciertos tipos de arquitectura sufrieron cuando fueron traducidos a un nuevo contexto geográfico" (2005: X y IX, respectivamente). En esta línea, tal vez uno de los principales difusores de la noción de "transculturización" en sede arquitectónica haya sido Gutiérrez, sobre todo si tenemos en cuenta la extensa difusión de sus trabajos en América Latina.

Gutiérrez abría el periodo de "dominio español" retomando las ideas que había publicado en Presencia y continuidad de España en la arquitectura rioplatense, en donde explicaba que para él "transculturización" implicaba tres modalidades: por impostación, por superposición y por mestizaje y que era la primera la que había predominado en el Río de la Plata (Gutiérrez, 1971: 5) ${ }^{23}$. Según su perspectiva, en la síntesis realizada por España en el continente -ese "sólo mundo latiendo al unísono"-, "se define el carácter periférico del Río de la Plata" que, "alejado del epicentro geopolítico del Caribe y satelizado desde Lima", cumplió un papel de proveedor de materias primas. Para agregar que "este carácter periférico es crucial, no solamente para entender la necesidad de una impostación inicial en la arquitectura, sino también cómo esta se manifiesta a través de una arquitectura espontánea" (Gutiérrez, 1984a: 33). Estas características originales -en tanto comienzo y marca- determinaron que "nuestra arquitectura fue intemporal y muy empírica, pero también así lo era en las zonas rurales marginadas de España" (Gutiérrez, 1984a: 34). Esta perspectiva

23 En ningún momento Gutiérrez da cuenta de las posibles fuentes de su noción de transculturización. 
Figura 2: La "arquitectura" del liberalismo
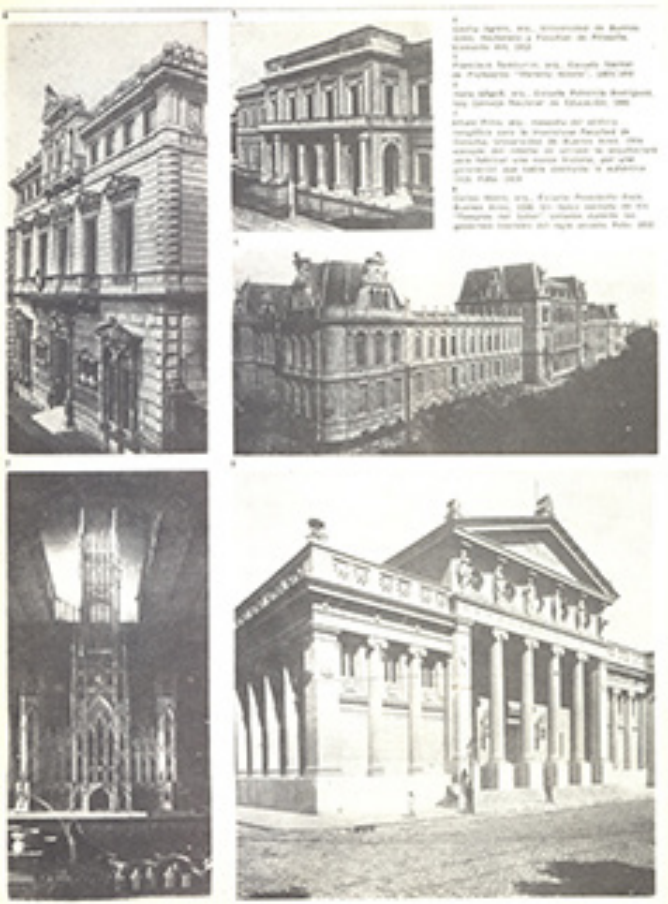

Fuente: Waisman (1984a: 92)

debe enmarcarse en la revisión comenzada en Anales, del que luego Gutiérrez sería uno de sus principales voceros, en la que se operó una inversión simétrica respecto a lo que se consideraba de valor en la arquitectura colonial: "aquello que era provinciano [para la historiografía europea] resulta ahora afirmación de lo americano (...) y el valor destacable para a ser el grado de incidencia popular en los programas de la cultura alta" (Aliata, 1999: 46). Por simétrica, esa inversión seguía sosteniéndose sobre una idea esencialista respecto a los procesos de transmisión cultural, muy lejos de la renovación en las teoría de la recepción que ya estaba llevando adelante Rama en los setenta, en un marco mayor de reformulaciones teóricas -por ejemplo "Las ideas fuera de lugar" de Roberto Schwarz o la "estética de la recepción" de Hans-Robert Jauss- que entendían que todo proceso de recepción contiene elementos activos que permitían reformular en nuevos términos toda esta problemática. La insistencia en esos viejos marcos conceptuales, junto a un vocabulario ligado a la "dependencia cultural" y a la "filosofía latinoamericana" -a lo Leopoldo Zea, Rodolfo Kush o Enrique Dussel-, resultaron centrales en una serie de posiciones sostenidas en los ochenta en torno al "regionalismo", a lo "propio" y a la "identidad" de la arquitectura latinoamericana en figuras como Gutiérrez, Cristian Fernández Cox, Enrique Browne e incluso, aunque en menor medida, en Waisman ${ }^{24}$. Pero más

24 Para un análisis más amplio del uso de las allá de esos debates, lo que nos interesa señalar es cómo ese núcleo conceptual afectó al trabajo historiográfico.

Como señalamos anteriormente, la arquitectura producida entre 1880 y 1930 fue una de las nuevas líneas de investigación que se abrieron en los sesenta, en cuya lectura del periodo primaron más los "ojos" del arquitecto que la "inteligencia" del historiador. Dicho de otra forma, en esos trabajos es posible ver hasta qué punto las auto representaciones de la cultura arquitectónica moderna obturaban toda posibilidad de entender el siglo XIX en sus propios términos. Al respecto, es iluminador la reflexión de Nicolini respecto a que su generación eran arquitectos modernos -por práctica profesional- pero que, por vocación historiográfica -y por ser discípulos de Buschiazzo- se identificaban con la arquitectura colonial ${ }^{25}$. Lo que permite entender que el análisis que se hace en $S / h$ del periodo se asiente sobre una contradicción y una doble valoración negativa: por un lado, se sostenía que el "eclecticismo" había sido un error que era necesario no volver a repetir, por el otro, no dejaba de señalarse la cantidad, magnitud y calidad de la obra construida entre 1880 y 1930 (Figura 2). Y esa valoración negativa reflejaba la consideración del historicismo y el eclecticismo decimonónico como de un "juego de máscaras", respecto de las cuales la arquitectura moderna había supuesto una ruptura y superación al aceptar la "era de la máquina". Estas ideas habían sido consagradas y difundidas a través de la historiografía de Pevsner, Giedion o Zevi y constituían un lugar común en los sesenta ${ }^{26}$. Así, por ejemplo, Ortiz (1984a: 77) decía que si se lograba entender por qué se dio el eclecticismo, "habremos dado un gran paso hacia la inoculación que nos mantendrá a salvo (ojalá) de esta perniciosa enfermedad"27. Pero

categorías de lo "nacional", "propio" y lo "ajeno" en la historiografía de la arquitectura argentina, véase Gorelik y Silvestri, 1990.

25 Comunicación con el autor, Tucumán, 30 de enero de 2017. Nicolini incluso comenta que en las clases de Buschiazzo casi no se hablaba del siglo XIX.

26 Pevsner (1994: 321-322) sostenía que en 1830 "la arquitectura se encontraba sumida en una situación alarmante tanto desde el punto de vista estético como social. Los arquitectos pensaban que cualquier creación de los siglos preindustriales era necesariamente mejor que cualquier obra que expresase el espíritu de su propia época". Por tanto, proseguía el autor, "a comienzo del siglo XIX nos encontramos con todo un despliegue carnavalesco de estilos arquitectónicos: clásico, gótico, italianizante, old-english".

27 Fue recién con el avance de la "arquitectura posmoderna", que en una de sus líneas rehabilitaba la arquitectura académica y la ciudad decimonónica, lo que posibilitó una mirada menos ideológicamente cargada sobre el siglo XIX. Un caso notable es el del propio Ortiz, que reformula sus posturas en su contribución -"Arquitectura, 1880-1930"- a la Historia general del arte en la Argentina de la Academia Nacional de Bellas Artes 
esa consideración se confundía con una valoración respecto al proceso de consolidación del Estado nacional, del que la arquitectura ecléctica terminaba siendo su manifestación más evidente: para Daniel Schávelzon y Héctor Karp (1984: 84) la "arquitectura de Estado" debía materializarse como "imagen de poder", de lo que se seguía que "el abuso del eclecticismo denota[ba] el proceso de transculturación de los valores gestados por el liberalismo europeo que vivió la burguesía local". Justamente el tipo de identificación directa entre arquitectura y política que había identificado Waisman como característica de la década en la cita con la que comienza este trabajo y que los autores había difundido en un artículo -"La arquitectura y el poder"- publicado de la revista Crisis en 1974.

En la misma línea, para Ricardo Jesse Alexander (1984a: 81) el proceso de afirmación nacional consistió en identificar lo nacional con lo universal-europeo. Esto implicó que "el resabio hispanizante del antecedente colonial y poscolonial debe ser erradicado a favor de una actualización, que implica, pues, una descriollización". La conclusión era que mientras el Estado produjo una "obra verdaderamente impresionante", el "vehículo expresivo fue de un eclecticismo tal que solo podía tener un resultado alienante. Hoy seguimos cosechando las consecuencias de dicha empresa, y la pregunta sigue pidiendo respuesta: ¿en dónde encontrar nuestra identidad?" (Alexander, 1984a: 82). De tal forma, a una mirada modernista que imposibilitaba entender la especificidad de la época, se le agregaba un valor extra disciplinar que hacía descansar en el "origen" colonial el momento irredento al que habría que volver para encontrar "nuestra identidad". Más aún, el eclecticismo -o sus variantes pintorescas- resultaban "ajenas a la raigambre hispánica - y por supuesto, ajenas al propio fermento americano que había creado su propio legítimo lenguaje" (Alexander, 1984b: 121). Por otro lado, ese "esencialismo" les llevaba a explicar -a Gutiérrez y Graciela Viñuelas (1984: 122)- la crisis del eclecticismo como una "crisis (...) de recursos formales, o en definitiva de agotamiento de recetas". Por tanto, para los autores la recepción del Art Nouveau resultaba en un hecho "superficial": "se aplican parietalmente a estructuras que no tienen dimensiones vitales con las de la Academia y a su manera son también eclécticas".

El neocolonial, por su parte, ya había sido abordado -aunque muy brevemente- por Ortiz (1968: 125) en La arquitectura del liberalismo, al indicar que se trataba del último de los "revivals" pero que procedía de una "auténtica revisión histórica, de una revalorización positiva de nuestro pasado histórico". Esta visión fue retomada y amplia-

de 1988, o en el libro de Glusberg Breve historia de la arquitectura en Argentina. da por Gutiérrez en Presencia y continuidad de España en la arquitectura rioplatense y por éste y Ortiz en La arquitectura en la Argentina, 19301970. Reproduciendo esos trabajos, Gutiérrez (1984b: 151) señalaba en s/h que "por su carácter pasatista el movimiento ["renacimiento colonial"] no consiguió integrarse a las corrientes contemporáneas y quedó reducido al anecdotario historicista". Por otra parte, la novedad en $S / h$ fue la de incorporar la figura de Juan Kronfuss -Gutiérrez había trabajado sobre Martín Noel y Ángel Guido-. Despreocupado por toda indagación sobre las especificidades de su desarrollo -por ejemplo, en relación con un campo intelectual más amplio del que se nutrió y al que le proveyó de imágenes, o como momento de experimentación y transición, como investigaciones posteriores de Liernur han mostrado-, el juicio que se expresaba en $s / h$ era contundente: "el balance del neocolonial es muy simple y conocido: buenas intenciones y magros resultados; buen planteo del problema (...) y soluciones deficientes por anti-históricas. Fue el último de los 'neos', tuvo la disculpa de intentar mirar para adentro"' (Nicolini et al, 1984: 158).

Si los análisis respecto al eclecticismo, el neocolonial, los diferentes revivales historicistas o el Art Nouveau quedaban atrapados en consideraciones de tipo formal o de estilo, las indagaciones respecto al periodo peronista mostraba hasta qué punto su caracterización quedó atrapada en las valoraciones interpretativas producidas poco tiempo después de Perón -como la producida por Gino Germani en clave sociológica-, en la que se mezclaban un disputa cultural que excedía a la arquitectura junto al prisma modernista que -como en el trabajo de Francisco Bullrichorganizaba la historia de la arquitectura sobre la base de la suerte del "movimiento moderno" en la Argentina. Esta yuxtaposición permitiría entender la persistencia de ver en el periodo peronista un tipo de arquitectura "fascista" -o "imperial" como la llama Gutiérrez- con analogía con lo que había sucedido en la Italia fascista -reproduciendo sin cuestionar el presupuesto que asimilaba arquitectura moderna a democracia-, sin recabar que ya el propio Germani había alertado sobre lo incorrecto de identificar fascismo y peronismo. Así, la mirada ambigua que ofrecía $S / h$ sobre el peronismo reproducía en sus líneas generales el relato canónico -con sentido teleológico- en el que este significaba un momento de freno y regresión para la arquitectura moderna. Habría que notar que mientras la querella entre peronismo y "modernismo" no había sido exclusiva de la arquitectura, sino que había sido compartida por un amplio sector de la cultura -como se sabe, Bullrich, al igual que muchos de los arquitectos modernos, participaba de los grupos más enfrentados al peronismo-, el consenso antiperonista se rompió al poco tiempo de la "revolución libertadora" y ya en los sesenta aparecieron nuevas interpretacio- 
nes sobre el "hecho peronista" -como las de Juan Carlos Portantiero y Miguel Murmis- que cuestionaban la de Germani. A la cultura arquitectónica, por su parte, le llevó mucho más tiempo revisar las relaciones con ese pasado. Incluso aún cuando aquella narración se sostenía sobre la base de una serie de olvidos de nombres y experiencias que, como ha demostrado Liernur (1986), resultaron ser de lo más significativas en el desarrollo de la arquitectura moderna en el país. La contradicción manifiesta, si se considera que buena parte de los autores de $s / h$ podían inscribirse en el campo de lo "nacional y popular", es que esa filiación no haya resultado en una relectura del periodo.

Esa dificultad de revisar el período peronista, aunque sea en términos historiográficos, es patente en el armado de $S / h$. Aún cuando se presenta evidencia de las principales apuestas del peronismo en clave moderna -como el Plan $\mathrm{Ca}-$ rrillo o la Ciudad Universitaria de Tucumán ${ }^{28_{-}}$, no alcanza para reformular la valoración del conjunto. Y esto es aún más evidente en cómo se mostraba el periodo. Al leer los apartados, se encuentra con una gran distancia entre lo que dicen las imágenes y lo que dice el texto. Plantas y cortes, pero sobre todo fotografías a página entera que muestran, de forma indiferenciada -por ejemplo, en una misma hoja aparecen la Municipalidad de Córdoba de SEPRA, el Teatro San Martin de Mario Roberto Álvarez, el edificio de Virrey del Pino de Kurchan y Ferrari Hardoy, entre otros (Figura 3)-, una impresionante producción arquitectónica moderna entre 1943 y 1955 que contrasta con la afirmación de Ortiz (1984b: 194) -tal vez la más negativa en $S / h$ - que sostenía que "marginada por el Estado, sin el patrocinio del sector privado, tildada de apátrida y casi siempre acusada de estar vinculada ideológicamente con el marxismo, la arquitectura contemporánea sobrevive en episodios aislados, a veces no exentos de mérito, pero sin trascender mayormente como fenómeno cultural" (Figura 4).

Ante esta visión maniquea, deberíamos complejizar la lectura de $s / h$. Efectivamente, las posturas respecto a este periodo no son unívocas y registran distintas capaz de sentido. Mientras la valoración del conjunto sigue siendo negativa, es posible advertir algún reconocimiento a las condiciones específicas de la producción arquitectónica durante el peronismo, así como a su sentido cultural o político para sectores más amplios que el de los profesionales. El caso más claro es respecto a la cuestión de la vivienda y al "estilo californiano". Así, por ejemplo, la difusión del estilo californiano ya no se leía exclusivamente como de regresión disciplinar, sino que se lo situaba como un intento de dar respuesta al

28 Posiblemente haya sido acá la primera vez que se publicaba el proyecto de Ciudad Universitaria.
Figura 3: Arquitectura Moderna durante el "nacionalismo popular" (1943-1955)
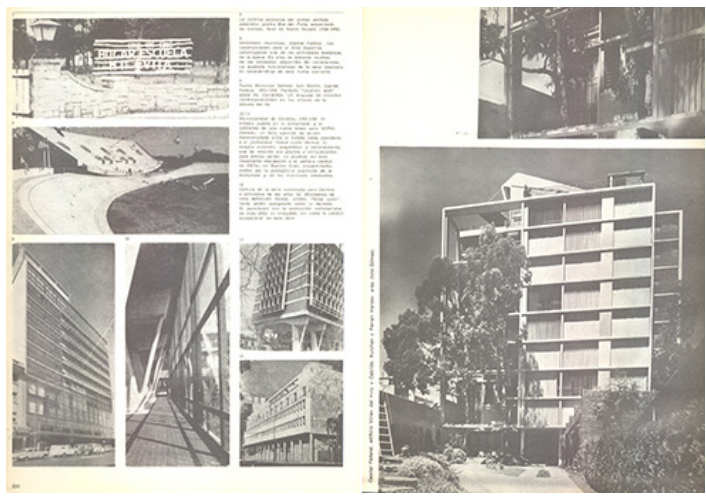

Fuente: Waisman, 1984a: 220-221

Figura 4: Arquitectura Moderna durante el periodo de "integración nacional" (1914-1943).

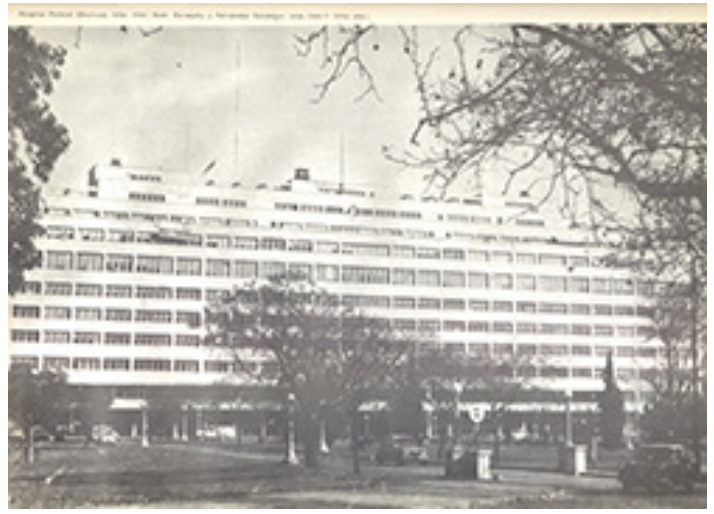

Fuente: Waisman, 1984a: 175

bagaje cultural que poseían los grupos sociales que apoyaban el peronismo. Al respecto, Jorge Cavallo, Carlos Hilger, María Isabel de Larrañaga y Alberto Petrina (1984: 217) sostenían que los migrantes del interior "en general provenientes de medios culturales de fuerte arraigo hispano-crioIlo, con ancestrales tradiciones de paternalismo familiar y caudillismo político, traía consigo una imagen largamente aprendida (...) de sus lugares físicos", para luego preguntarse, respecto a las soluciones disciplinares que se ofrecían, si "¿primaría el respeto por el destinatario, como persona con una historia y con necesidades precisas, o el gusto del arquitecto, imponiendo su propio criterio acerca de cómo los demás deben vivir su propia vida?", su respuesta era que "en realidad, y contra la opinión generalizada, que señala sólo la primera de estas opciones, se siguió un camino de síntesis entre ambas", para concluir, citando a Ortiz y Gutiérrez, que "si los resultados cualitativos pueden dejar mucho que desear no podemos, sin embargo, menos que admirarnos de lo cuantitativamente realizado".

En realidad, este panorama confuso respecto al peronismo ya estaba presente en La arquitectura en la Argentina de Ortiz y Gutiérrez. Allí 
se sostenía que "la política de Perón significó la incorporación de los sectores marginales en las decisiones de poder, aunque ello no alteró sustancialmente las estructuras. La clase trabajadora tomó conciencia de su papel protagónico en el proceso y en el principio mejoraron sensiblemente sus condiciones de vida" (Ortiz y Gutiérrez, 1972: 34). Para luego proceder a una identificación entre peronismo y fascismo, por lo menos a nivel arquitectónico. Así, los autores sostenían que en "Argentina esta arquitectura de masas [las obras de Albert Speer o la Exposición Universal de Roma] había sido y seguiría siendo expresión de la dependencia cultural, manifestada como préstamo de sistemas icnológicos cuyo contenido era y es aceptado o marginado, sin mayores desasosiegos", para agregar que desde el ministerio de guerra (1938-1942), la Facultad de Derecho (1942-1949), la sede de la Fundación Eva Perón (1950-52) y hasta el monumento a la Bandera de 1940 eran claros ejemplos de "arquitectura imperial", lo que los llevaba a concluir que subyacía a esa "etapa la negación apocalíptico del racionalismo arquitectónico" (Ortiz y Gutiérrez, 1972: 42). Estas consideraciones fueron reproducidas por Gutiérrez (1984c) en el apartado la "arquitectura imperial", con el que se abre los años relativos al peronismo (como buscando un golpe de efecto, aparece en la misma secuencia una foto del Graf Zeppelin -reconocido símbolo del régimen nazi- sobre el Luna Park (Figura 5). El problema con estas afirmaciones no era tanto que se tomara al Estado como un todo homogéneo, que se omitieran grupos y trayectorias, ni que no se diera cuenta de debates y polémicas, sino que lo que más sorprende en esa identificación entre fascismo y peronismo es que los casos que se menciona, a excepción de la Fundación Eva Perón, fueron edificios construidos o proyectados con anterioridad al peronismo.

\section{Epilogo}

Como señalamos antes, el emprendimiento de $S / h$ contribuyó decididamente al proceso de reconstitución del campo de la historiografía de

Figura 5: "Arquitectura Imperial"

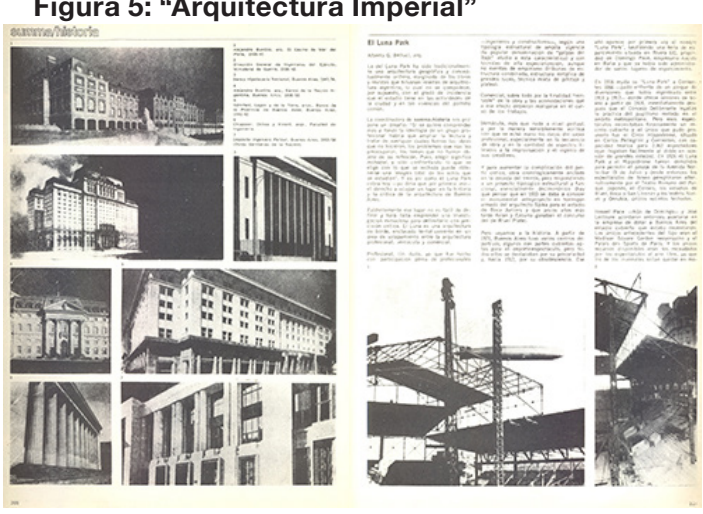

Fuente: Waisman, 1984a: 206-207 la arquitectura, en tanto supuso el primer intento de ofrecer una historia integral de la arquitectura en el país, lo que implicó una empresa colectiva que revitalizó redes y contactos forjados previamente. Justamente, algunas de las derivas de $S / h$ permiten dan cuenta de la continuación de esos contactos, los que comentaré brevemente. La publicación en formato libro de s/h en 1978 coincidió con la creación del Instituto Argentino de Investigaciones en Historia de la Arquitectura y el Urbanismo (IAIHAU). La idea surgió de un encuentro organizado por Raúl Gómez Crespo y Roberto Cova en Mar del Plata en marzo de 1978. En septiembre se realizó un nuevo encuentro en Tucumán donde quedó oficialmente establecido el Instituto, quedando Nicolini como su presidente. El Instituto reflejaba las precarias condiciones en que se encontraban las universidades argentinas durante la dictadura y, al igual que "la Escuelita", surgió de la iniciativa privada, desarrollándose por fuera de todo marco institucional oficial. Esto no impidió que el IAIHAU se constituyera en el espacio de referencia de la historia de la arquitectura, consolidando las redes que venimos describiendo. Más aún, a partir del número siete, DANA se convirtió en el vocero oficial del Instituto, a lo que le debemos sumar la articulación que llevó adelante Waisman entre el IAIHAU y el Curso de Posgrado de Historia y Preservación del Patrimonio en la Universidad Católica de Córdoba. Si los primeros congresos del IAIHAU retomaban tópicos que se venían trabajando desde finales de los sesenta -como el de la arquitectura popular-, a partir del V congreso en 1981 se volvió central la cuestión del patrimonio, coincidentemente con su ingreso en las agendas de discusión pública, como lo muestra la repercusión del Congreso de Preservación del Patrimonio que se realizó en Buenos Aires ese año. Justamente, esto da cuenta de una deriva desde la historia a las temáticas del patrimonio y la conservación que permite comprender, por lo menos en parte, por qué no se produjo una profesionalización disciplinar de las redes que habían convergido en $s / h$-entendiendo por tal una formación específica en historiografía-.

Además de los congresos, el IAIHAU tuvo una activa política de edición: por un lado, se comenzó a editar una "segunda época" y una "tercera época" de s/h en Summa que, en los planes de Waisman, deberían haber formado un estudio más amplio de la historia de la arquitectura en la argentina de tres tomos -del que sólo se llegó a editar el primero, correspondiente al periodo coIonial-. Por otro, publicó entre 1982 y 1987, en colaboración con la SCA, El patrimonio arquitectónico de los argentinos. Si bien estaban programados diez tomos, sólo salieron al público cuatro (dos sobre el noroeste, uno sobre el noreste y uno sobre Córdoba). La SCA también le encargó al IAIHAU, con un equipo coordinado por Gutiérrez, 
un libro con la historia de la entidad por los 100 años de su existencia.

Por último, y para concluir, debemos señalar, aunque no podemos explayarnos en el tema, que las redes generadas en torno a Waisman, Gutiérrez y el IAIHAU contrastan con las que fue construyendo Francisco Liernur a su vuelta de Italia, donde había estudiado con Manfredo Tafuri entre 1974 y 1976. Primero en La Escuelita, donde dictó diferentes cursos, para luego armar el Programa de Estudios Históricos de la Construcción del Habitar en el Centro de Estudios en la Sociedad Central de Arquitectos que aglutinó a una nueva generación de historiadores de la arquitectura. La propuesta historiográfica de Liernur se pensó programáticamente en un cruce con las líneas renovadoras de la historia social y cultural que se estaban consolidando en los tempranos ochenta, impulsados desde Punto de vista. De tal forma, para principio de los ochenta comenzó a evidenciarse un proceso de una diversificación del campo de la historiografía de la arquitectura. 


\section{Bibliografía}

Alexander, R. (1984a). La arquitectura del nordeste y noroeste argentinos después de 1880: los edificios de gobierno y la significación de sus formas. En: Waisman, M. (Coord.). Documentos para una historia de la arquitectura argentina. Buenos Aires: Ediciones Summa, pp. 81-82.

Alexander, R. (1984b). El pintoresquismo en la arquitectura argentina. Una reflexión. En: Waisman, M. (Coord.). Documentos para una historia de la arquitectura argentina. Buenos Aires: Ediciones Summa, pp. 121-122.

Aliata, F. (1999). Neoclasicismo en el Río de la Plata. Fuentes y construcción historiográfica. En AA. VV. Gli archivi per la storia dell'architettura. Roma: Ministero dei Beni Ambientali et Culturali. Archivio di Stato di Reggio Emilia, pp. 44-53.

Bayón, D. (1970). Hacia un nuevo enfoque del arte colonial sudamericano. Anales del IAA (23), pp. 17-32.

Buschiazzo, M. (1969). El problema del arte mestizo. Anales del IAA (22), pp. 84-102.

Cavallo, J., Hilger, C., de Larrañaga, M. I., y Petrina, A (1984). Análisis crítico del diseño arquitectónico en el periodo. En: Waisman, M. (Coord.). Documentos para una historia de la arquitectura argentina. Buenos Aires: Ediciones Summa, pp. 213-215.

Canavese, M. (2015). Los usos de Foucault en la argentina. Recepción y circulación desde los años cincuenta hasta nuestros días. Buenos Aires: Siglo XXI.

de Paula, A. (1997). Mario Buschiazzo y el Instituto de Arte Americano. Anales del IAA (31-32), pp. $15-42$.

Devoto, F. y Pagano, N. (2009). Historia de la historiografía argentina. Buenos Aires: Sudamericana. Eco, U. (1972). El antidiseño. Summa (54) octubre.

García, L. (2011). La crítica entre culturas. Estética, política, recepción. Santiago de Chile: Universidad de Chile.

Gazaneo, J. (1970). Presentación. Anales (24).

Gorelik, A. y Silvestri, G. (1988). Arquitectura e ideología: los recorridos de lo 'nacional y popular'”. $\operatorname{RdA}(141)$, pp. 50-61.

Gorelik, A. y Silvestri, G. (1990). Lo nacional en la historiografía de la arquitectura en la Argentina: el peso de la tradición. En Comité Internacional de Ciencias Históricas. Comité Argentino. Historiografía argentina (1958-1988). Una evaluación crítica de la producción histórica argentina. Buenos Aires: ClCH. pp. 174-187

Gutiérrez, R. (1971). Presencia y continuidad de España en la arquitectura rioplatense. Buenos Aires: Concentra.

Gutiérrez, R. (1984a). Transculturización y espontaneidad. En: Waisman, M. (Coord.). Documentos para una historia de la arquitectura argentina. Buenos Aires: Ediciones Summa, pp. 33-34.

Gutiérrez, R. (1984b). Una nueva propuesta: el renacimiento colonial. En: Waisman, M. (Coord.). Documentos para una historia de la arquitectura argentina. Buenos Aires: Ediciones Summa, pp. 151-153.

Gutiérrez, R. (1984c). "La arquitectura imperial". En: Waisman, M. (Coord.). Documentos para una historia de la arquitectura argentina. Buenos Aires: Ediciones Summa, p. 205-.

Gutiérrez, R. y Paterlini, O. (2007). IIDEHA. Historia de la arquitectura en la Argentina. Reflexiones de medio siglo. Buenos Aires: CEDODAL.

Gutiérrez, R. y Viñuelas, G. (1984). El antiacademicismo y el Art Nouveau. En: Waisman, M. (Coord.). Documentos para una historia de la arquitectura argentina. Buenos Aires: Ediciones Summa, pp. 122124.

Hernández, F. (2005). Introduction: Transcultural Architecture in Latin America. En Hernández, F., Millington, M., Borden, I. Transculturation. Cities, Spaces and Architectures in Latin America. Amsterdam: Rodopi, pp. IX-XXV.

Liernur, J. F (1986). El discreto encanto de nuestra arquitectura 1930 / 1960. Summa (223), pp. 60-79.

Malecki, J. S. (2013). Historia y crítica. Enrico Tedeschi en la renovación de la cultura arquitectónica argentina, 1950-1970. Eadem Utraque Europa (14), pp. 137-174.

Malecki, J. S. (2014). La ciudad dislocada: Córdoba, 1947-1975. Modernización y radicalización en la cultura urbana y arquitectónica (Tesis de Doctorado inédita), Universidad Nacional de Córdoba, Facultad de Filosofía y Humanidades.

Malecki, J. S. (2016). Crisis, radicalización y política en el Taller Total de Córdoba, 1970-1975. Prohistoria (25), pp. 79-103.

Martini, J. X. (1971). Notas para una crítica de la arquitectura colonial argentina. Anales del IAA (24), pp. 9-21.

Nicolini, A. (2007). Medio siglo de enseñanza. En: Gutiérrez, R. y Paterlini, O. IIDEHA. Historia de la arquitectura en la Argentina. Reflexiones de medio siglo. Buenos Aires: CEDODAL, pp. 19-24. 
Nicolini, A., Ceballos, E., Romaña, C., Wagner, R. (1984). La restauración nacionalista en la arquitectura del noreste. En: Waisman, M. (Coord.). Documentos para una historia de la arquitectura argentina. Buenos Aires: Ediciones Summa, pp. 155-158.

Pando, H. (1997). Recuerdos del IAA y de su fundador Mario J. Buschiazzo. Origen y desarrollo del Instituto de Arte Americano. Anales del IAA (31-32), pp. 143-154.

Pevsner, N. (1994). Breve historia de la arquitectura europea. Madrid: Alianza.

Ortiz, F. (1984a). La arquitectura argentina después de 1880: una introducción. En: Waisman, M. (Coord.). Documentos para una historia de la arquitectura argentina. Buenos Aires: Ediciones Summa, pp. 77-80.

Ortiz, F. (1984b). Resumen de la arquitectura argentina desde 1925 hasta 1950. En: Waisman, M. (Coord.). Documentos para una historia de la arquitectura argentina. Buenos Aires: Ediciones Summa, pp. 191-194.

Ortiz, F y Gutiérrez, R. (1972). La arquitectura en la argentina 1930-1970. Buenos Aires: Concentra.

Ortiz, F., Mantero, F., Gutiérrez, R., Levaggi. A. (1968). La arquitectura del liberalismo en la Argentina. Buenos Aires: Sudamericana.

Raversa, R. (2010). En torno a la semiótica en Argentina, Editorial del Cardo. Recuperado de: http:// www.biblioteca.org.ar/libros/154508.pdf.

Schávelzon, D y Karp, H (1984). La arquitectura del estado liberal. En: Waisman, M. (Coord.). Documentos para una historia de la arquitectura argentina. Buenos Aires: Ediciones Summa, pp. 155-158.

Silvestri, G. (2004). Historiografía de la arquitectura. En Liernur, J. F. y Aliata, F. (Comps.). Diccionario de Arquitectura en Argentina. Buenos Aires: AGEA.

Tafuri, M (1972). Design and Technological Utopia, citado en Scott. F. (2010) Technoutopias. Politics After Modernismo. Cambrige: MIT Press, p. 136.

Tarcus, H. (1999). El corpus marxista. En: Cella, S. Historia crítica de la literatura argentina. La irrupción de la crítica. Buenos Aires: Emece, pp. 465-500.

Tedeschi, E. (1956). La enseñanza de la arquitectura. Nuestra Arquitectura (318).

Tedeschi, E. (1957). Sobre los métodos de enseñanza de la arquitectura. Nueva Visión (9).

UNT (1957). La Enseñanza de la historia de la Arquitectura. Reuniones docentes realizadas en Tucumán del 8 al 11 de abril de 1957. Tucumán: UNT.

Vidler, A. (2008). Histories of the Immediate Present. Cambridge: The MIT Press.

Waisman, M. (1970). Umberto Eco en IIDEHA. Summa (29) septiembre.

Waisman, M. (1980). Argentina: la conflictiva década del 70. Summa (157).

Waisman, M (Coord.) (1984a). Documentos para una historia de la arquitectura argentina. Buenos Aires: Ediciones Summa.

Waisman, M (1984b). Advertencia. En: Waisman, M. (Coord.). Documentos para una historia de la arquitectura argentina. Buenos Aires: Ediciones Summa, pp. 7-8.

Waisman, M. (1985). La estructura histórica del entorno. Buenos Aires: Nueva Visión, primera edición 1972. 